\title{
The QseB/QseC two-component system contributes to virulence of Actinobacillus pleuropneumoniae by downregulating apf gene cluster transcription
}

\author{
Benzhen Duan ${ }^{1,2}$, Wei Peng ${ }^{1,2}$, Kang Yan ${ }^{1,2}$, Feng Liu ${ }^{1,2}$, Jia Tang ${ }^{1,2}$, Fengming Yang ${ }^{1,2}$, Huanchun Chen ${ }^{1,2}$,
} Fangyan Yuan ${ }^{3^{*}}$ and Weicheng Bei ${ }^{1,2,4,5^{*}}$ (i)

\begin{abstract}
Actinobacillus pleuropneumoniae (APP) is the major pathogen of porcine contagious pleuropneumoniae (PCP). The QseB/QseC two-component system (TCS) consists of the regulator QseB and the kinase QseC, which relates to quorum sensing (QS) and virulence in some bacteria. Here, we investigated the role of QseB/QseC in apf gene cluster ( $a p f A B C D$ ) expression of APP. Our results have showed that QseB/QseC TCS can potentially regulate the expression of apf gene cluster. The $\triangle q s e B C, \triangle a p f A, \triangle a p f B, \triangle a p f C$ and $\triangle a p f D$ strains are more sensitive to acidic and osmotic stressful conditions, and exhibite lower biofilm formation ability than wild-type (WT) strain, whereas the complemented strains show similar phenotype to the WT strain. In additon, the mutants have defective antiphagocytosis, adhesion and invasion when they come into contact with the host cells. In experimental animal models of infection, mice infected with $\triangle q s e B C, \triangle a p f A, \triangle a p f B, \triangle a p f C$ and $\triangle a p f D$ strains showed lower mortality and bacterial loads in the lung and the blood than those infected with WT strain. In conclusion, our results suggest that QseB/QseC TCS contributes to stress resistance, biofilm formation, phagocytosis, adhesion, invasion and virulence by downregulating expression of apf gene cluster in A. pleuropneumoniae.
\end{abstract}

Keywords: A. pleuropneumoniae, QseB/QseC, Transcriptional regulation, apf gene cluster, Virulence

\section{Background}

Porcine contagious pleuropneumoniae (PCP) is a highly infectious porcine respiratory disease, which is caused by Actinobacillus pleuropneumoniae (APP). This disease is widespread in many countries and has brought great loss to farming and animal husbandry enterprises (González et al. 2017). Clinically, PCP is mainly characterized by acute fibrinous hemorrhagic pleuropneumonia and chronic

\footnotetext{
*Correspondence: fangyanyuan12@163.com; beiwc@mail.hzau.edu.cn ${ }^{3}$ Key Laboratory of Prevention and Control Agents for Animal Bacteriosis (Ministry of Agriculture), Institute of Animal Husbandry and Veterinary Sciences, Hubei Academy of Agricultural Sciences, Wuhan, China 'State Key Laboratory of Agricultural Microbiology, College of Veterinary Medicine, Huazhong Agricultural University, Wuhan, China

Full list of author information is available at the end of the article
}

fibrinous necrotizing pleuropneumonia (Sassu et al. 2018). So far, APP is divided into 2 biotypes and 19 serovars (Bosse et al. 2018; Sassu et al. 2018; To et al. 2021; Stringer et al. 2021). Some factors associated with virulence such as toxins, lipopolysaccharide, adhesion molecules, and outer membrane proteins contribute to the pathogenicity (Chiers et al. 2010).

To improve the adaptability of bacteria, their changing environment can be sensed and responded by the twocomponent systems (TCSs) (Jacob-Dubuisson et al. 2018). The bacterial TCS consists of a histidine kinase (HK) and a response regulator (RR) (Buelow and Raivio 2010). When the HK transfers a phosphate group to the $R R$, the $R R$ can directly or indirectly regulate the

(c) The Author(s). 2022 Open Access This article is licensed under a Creative Commons Attribution 4.0 International License, which permits use, sharing, adaptation, distribution and reproduction in any medium or format, as long as you give appropriate credit to the original author(s) and the source, provide a link to the Creative Commons licence, and indicate if changes were made. The images or other third party material in this article are included in the article's Creative Commons licence, unless indicated otherwise in a credit line to the material. If material is not included in the article's Creative Commons licence and your intended use is not permitted by statutory regulation or exceeds the permitted use, you will need to obtain permission directly from the copyright holder. To view a copy of this licence, visit http://creativecommons.org/licenses/by/4.0/. The Creative Commons Public Domain Dedication waiver (http://creativecommons.org/publicdomain/zero/1.0/) applies to the data made available in this article, unless otherwise stated in a credit line to the data. 
expression levels of downstream genes (Vogt and Raivio 2012). Genomic sequencing has revealed that there are 5 putative TCS in APP: QseB/QseC (YgiX/YgiY), CpxR/ CpxA, PhoB/PhoR, NarP/NarQ and ArcA/ArcB (Xu et al. 2008).

Quorum sensing (QS) is identified as a cell density sensing phenomenon, which utilizes autoinducers, or bacterial hormone-like compounds (Mukherjee and Bassler 2019; Li et al. 2021). As autoinducers reach a certain concentration, the signaling molecules can be involved in regulating certain genes expression (Lerat and Moran 2004). According to the sequence similarity, there are two QS systems called LuxS and QseB/QseC in APP. Previous studies have shown that LuxS is closely associated with infection of APP (Li et al. 2011). QseB/ QseC of APP is a putative TCS with high homology to the YgiX/YgiY system of Escherichia coli and QseB/ QseC system of Erwinia and Haemophilus (Liu et al. 2015). In recent years, QseB/QseC TCS has been linked to the virulence of Enterobacteriaceae and Pasteurellaceae (Weigel and Demuth 2016). The QseB/QseC TCS has also been confirmed to contribute to the biofilm formation of Aggregatibacter actinomycetemcomitans (Novak et al. 2010), Salmonella enterica (Ji et al. 2017) and $E$. coli ( $\mathrm{Li}$ et al. 2020). In addition, the QseB/QseC TCS is related to the stress resistance of $E$. coli (Li et al. 2020).

Previous studies have confirmed that QseB/QseC TCS regulates the expression of pilM, which encodes a type IV pili (Tfp) assembly protein (Liu et al. 2015), and contributes to virulence, biofilm formation and stress resistance in some bacteria (Novak et al. 2010; Yang et al. 2021). However, the function of QseB/QseC TCS in APP is not fully revealed. In this study, we have shown that QseB/QseC TCS positively regulates the expression of apf gene cluster, which also encodes Tfp assembly protein. RNA-seq, quantitative reverse transcription PCR (RT-qPCR) and electrophoretic mobility shift assay (EMSA) were used to screen downstream genes potentially regulated by $\mathrm{QseB} / \mathrm{QseC} \mathrm{TCS}$. It was found that the RR QseB could bind to the promoter of apf gene cluster. The $\triangle q s e B C, \triangle a p f A, \triangle a p f B, \triangle a p f C$, and $\triangle a p f D$ strains significantly contribute to stress resistance, biofilm formation, phagocytosis, adhesion, invasion and virulence in APP. Our results provide a basis for further understanding the QseB/QseC TCS and apf gene cluster function in bacteria.

\section{Results}

\section{QseB/QseC TCS influences transcription of apf gene} cluster

We constructed $\triangle q s e B C$ mutant and its complemented strain $(C \triangle q s e B C)$ and investigated the expression of apf gene cluster in WT, $\triangle q s e B C$ and $C \triangle q s e B C$ strains by
RT-qPCR. It was found that the transcription levels of the genes in the apf gene cluster were downregulated significantly in $\triangle q s e B C$ strain than that in WT and $\mathrm{C} \triangle q s e B C$ strains (Fig. 1).

\section{QseB can bind to the promoter of apf gene cluster} SDS-PAGE results showed that the QseB $(28.64 \mathrm{KDa})$ was successfully expressed and purified (Fig. 2). We performed EMSAs using purified QseB protein with DNA fragments containing the putative promoter regions of apf gene cluster, pilM (positive control), and glpK (negative control), respectively. Results revealed that QseB can bind to the promoter regions of apf gene cluster (Fig. 3a) and pilM (Fig. 3b), however not to that of $g l p K$ (Fig. 3c). These data suggested that transcription of apf gene cluster, and pilM, but not $g l p K$ was regulated by QseB.

\section{Role of $q s e B C$ and apf in environmental stress resistance of APP strains}

Next, $\triangle a p f A, \triangle a p f B, \triangle a p f C, \triangle a p f D$ mutants and the corresponding complemented strains were constructed. When the bacteria were exposed to $0.02 \mathrm{M} \mathrm{HCl}$-induced acidic or $0.50 \mathrm{M} \mathrm{KCl}$-induced osmotic stress, the count of live bacteria of the $\triangle q s e B C, \triangle a p f A, \triangle a p f B, \triangle a p f C$ and $\triangle a p f D$ strains were lower compared with those of WT strain at $3 \mathrm{~h}$ (Fig. 4).

\section{Contribution of $q s e B C$ and apf to biofilm formation of APP}

Previous studies have reported that A. pleuropneumoniae S4074 strain can form significant biofilm in BHI (supplemented with NAD) (Labrie et al. 2010). As expected, a robust biofilm was observed in WT strain, however the biofilm formation abilities of $\triangle q s e B C$, $\triangle a p f A, \triangle a p f B, \triangle a p f C$ and $\triangle a p f D$ were lower than that of WT strain. The quantitative evaluation of these biofilms confirmed that biofilm formation was significantly impaired in $\triangle q s e B C$ and $\triangle a p f A B C D$ mutants compared to WT and the complemented strains (Fig. 5).

\section{The qseBC and apf gene cluster contribute to the} resistance to phagocytosis, adhesion and invasion of APP to host cells

To investigate whether the qseBC and apf gene cluster contribute to the resistance to phagocytosis, adhesion and invasion, $\triangle q s e B C, \triangle a p f A, \triangle a p f B, \triangle a p f C, \triangle a p f D$ and the complemented strains were examined for their phagocytosis of RAW264.7, adhesion and invasion to NPTr cells, and the WT strain was used as a control. It was found that the $\triangle q s e B C, \triangle a p f A, \triangle a p f B, \triangle a p f C$ and $\triangle a p f D$ mutants had defective anti-phagocytosis of RAW264.7 macrophage (Fig. 6a) and the abilities of 


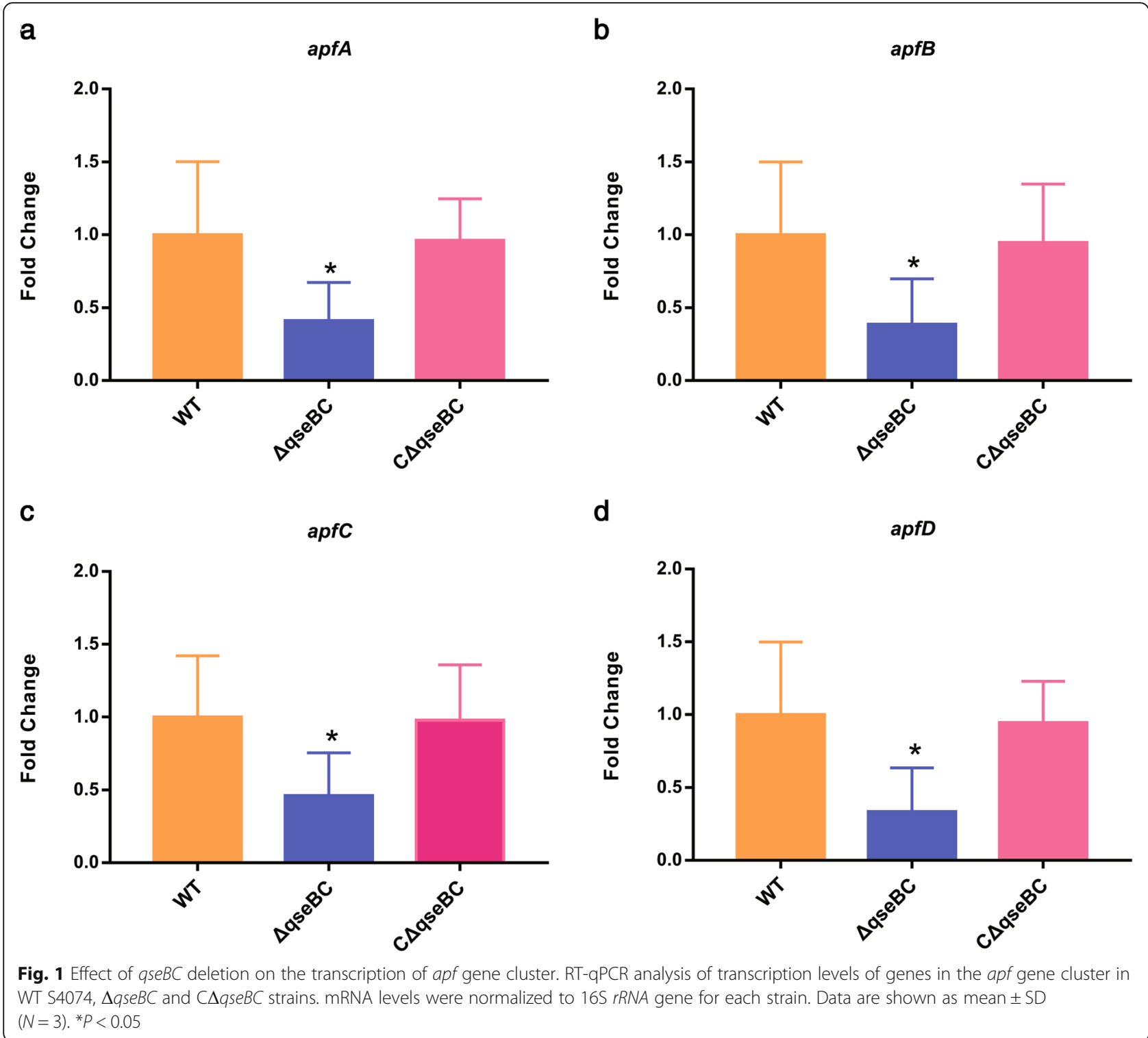

adhesion (Fig. 6b) and invasion to NPTr cells (Fig. 6c) were lower than those of WT and the complemented strains.

\section{Virulence of the $\triangle q s e B C$ and $\Delta a p f$ gene cluster mutants in} mice

The virulence of $\triangle q s e B C$ and $\triangle a p f$ gene cluster mutants was investigated by using Balb/c mouse models of APP in vivo (Xie et al. 2016). We found that the Survival rates of mice at $120 \mathrm{~h}$ were $16.67,16.67,83.33,66.67$, 66.67, 66.67, 0, 0, 0, 16.67 and 0 for WT, $\triangle q s e B C$, $\triangle a p f A, \quad \triangle a p f B, \Delta a p f C, \triangle a p f D, C \Delta q s e B C, C \Delta a p f A$, $\mathrm{C} \triangle a p f B, C \Delta a p f C$ and $C \Delta a p f D$-infected groups, respectively (Fig. 7a). Although the survival of mice at $120 \mathrm{~h}$ were equal in WT and $\triangle q s e B C$ groups, it was interesting that the survival of mice infected with $\triangle q s e B C$ (83.33) was significantly higher than that of WT (50.00) at $6 \mathrm{~h}$ post-infection. Furthermore, the bacterial loads of the $\triangle q s e B C, \triangle a p f A, \triangle a p f B, \triangle a p f C$ and $\triangle a p f D$ strains in the lung (Fig. 7b) and the blood (Fig. 7c) were lower than those by WT and the complemented strains at $6 \mathrm{~h}$ postinfection $(P<0.05)$. Taken together, our results suggest that QseB/QseC TCS and apf gene cluster may contribute to the virulence in the early stage of infection of A. pleuropneumoniae.

\section{Discussion}

The QseB/QseC TCS is considered as a regulatory system that relates to quorum sensing. Previous studies have revealed that QseB/QseC TCS contributes to interboundary signal transduction and regulation of virulence gene expression, as well as toxin production (Clarke 


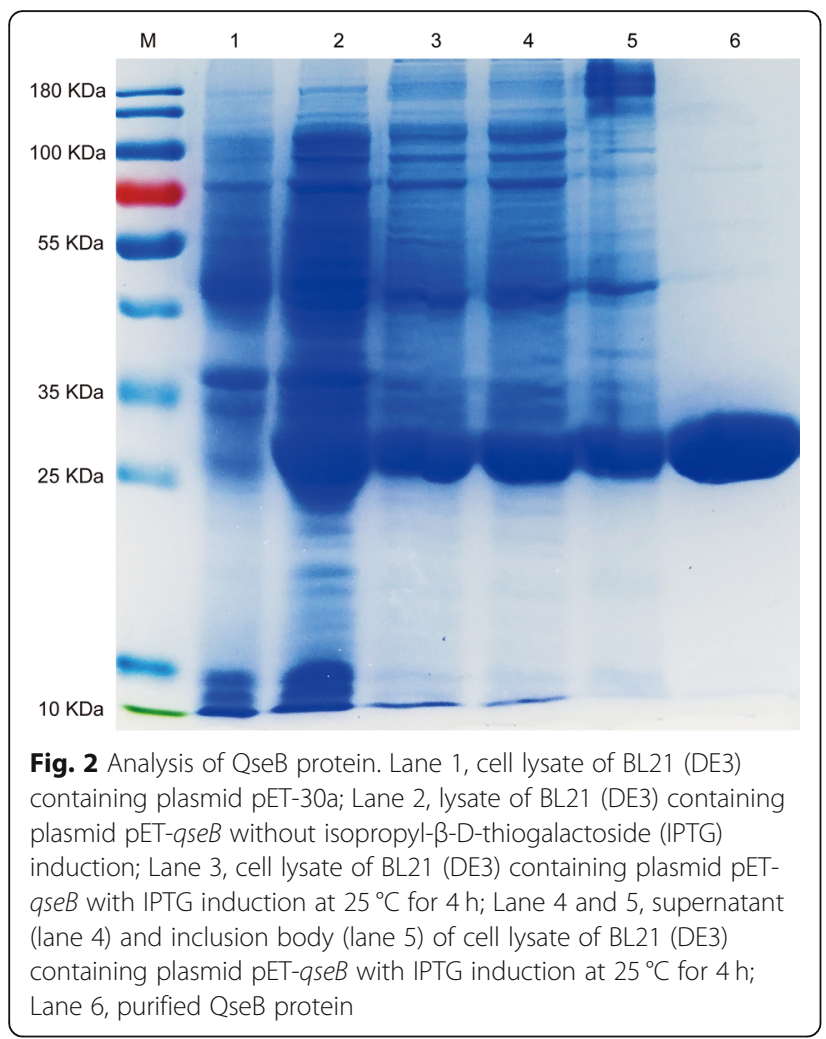

et al. 2006). Khajanchi et al. have demonstrated that QseB/QseC TCS can regulate virulence of APP in vitro and in vivo (Khajanchi et al. 2012). It has been reported that the inactivation of $\mathrm{QseB} / \mathrm{QseC}$ leads to a decrease in biofilm formation of $E$. coli ( $\mathrm{Li}$ et al. 2020). Bearson and Bearson have also found that QseB/QseC is involved in $S$. typhimurium colonization of swine (Bearson and Bearson 2008).

In this study, the EMSAs were performed to detect the regulatory relationships between QseB and apf gene cluster. Initially, purified QseB protein was directly used for EMSAs, but it was found that QseB could not bind to the promoter of apf gene cluster and pilM (positive control). Yan et al. demonstrated that phosphorylated CpxR protein could bind to the promoter of wecA in APP (Yan et al. 2020). Then we phosphorylated the QseB protein and found that phosphorylated QseB could bind to the promoter of and apf gene cluster and pilM (positive control). The results suggest that phosphorylated QseB might regulate the transcription of apf gene cluster.

Our results presented here demonstrate that the $\triangle q s e B C$ and $\triangle a p f$ gene cluster mutants are more sensitive to acidic and osmotic stressful conditions than WT the and complemented strains, which are consistent with earlier studies (Li et al. 2020). The $\triangle q s e B C$ and $\triangle a p f$ gene cluster mutants also exhibite lower biofilm formation ability than WT strain and the complemented mutants. Biofilm is an extracellular polymer formed on the surface of bacterial colonies, which can cause selfagglutination and adhesion of bacteria. Biofilms of many strains of APP have been detected and are thought to relate to bacterial colonization (Kaplan et al. 2004; Kaplan and Mulks 2005). Taken together, our results suggest that QseB/QseC affects stress resistance and biofilm formation by regulating the expression of apf gene cluster.

In addition, this research suggests that the virulence of $\triangle q s e B C$ and $\triangle a p f$ gene cluster mutants were more attenuated than that of WT and the complemented strains in the mouse infection models. Liu et al. used a pig infection model to evaluate the virulence of $\triangle q s e B C$ of $A$. pleuropneumonia, and measured the clinical signs such as appetite, dyspnea, lethargy and fever of the infected pigs at 12 , 24, 36, 48 and $60 \mathrm{~h}$. They found that there was no significant difference between the clinical scores of the pigs inoculated with $\triangle q s e B C$ mutant and WT, indicating that QseB/QseC had no significant effect on the virulence

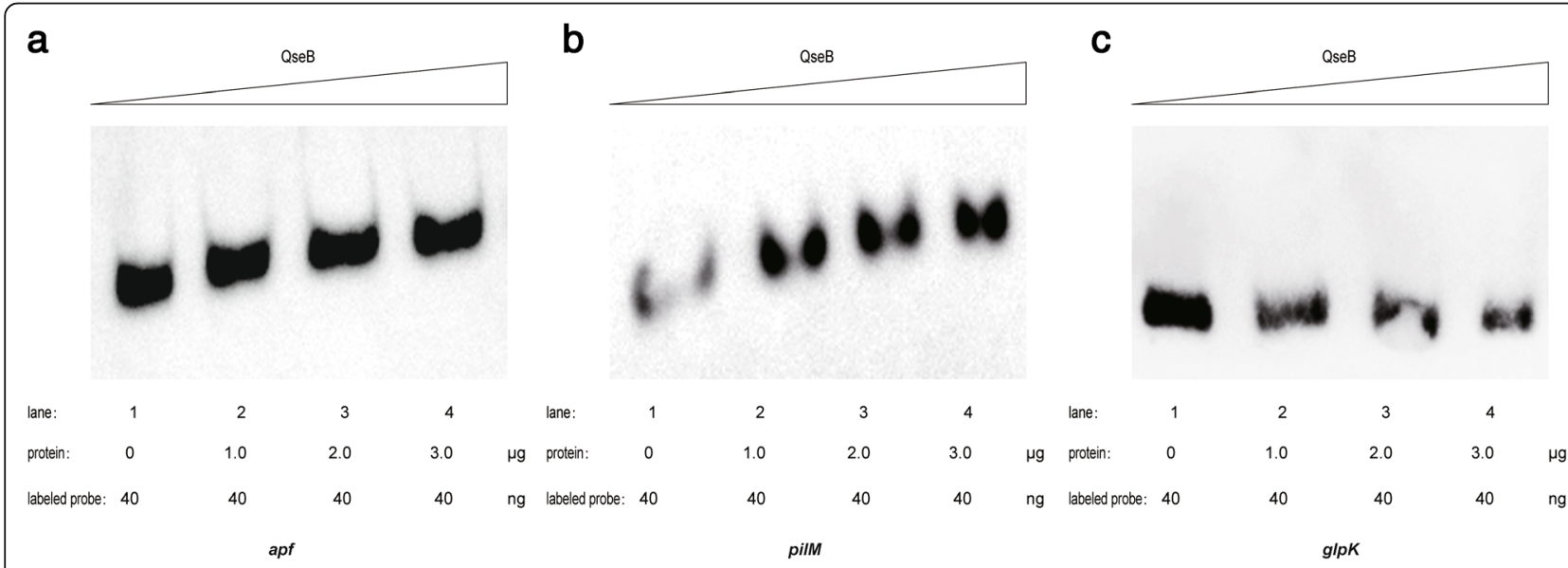

Fig. 3 Electrophoretic mobility shift assay of interaction between QseB and the promoter regions. Different amount of purified QseB protein was incubated with DNA fragment of promoter region of apf (a), pilM (positive control) (b) and glpK (negative control) (c) 
a

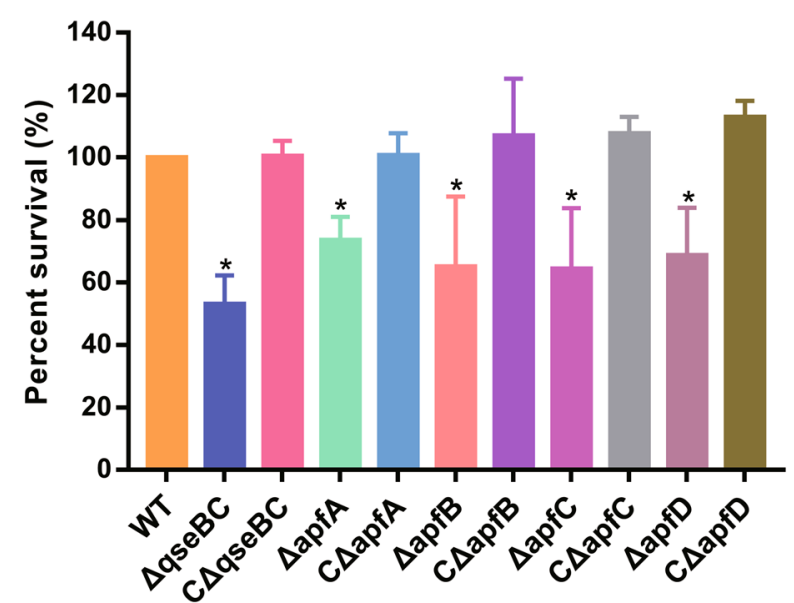

b

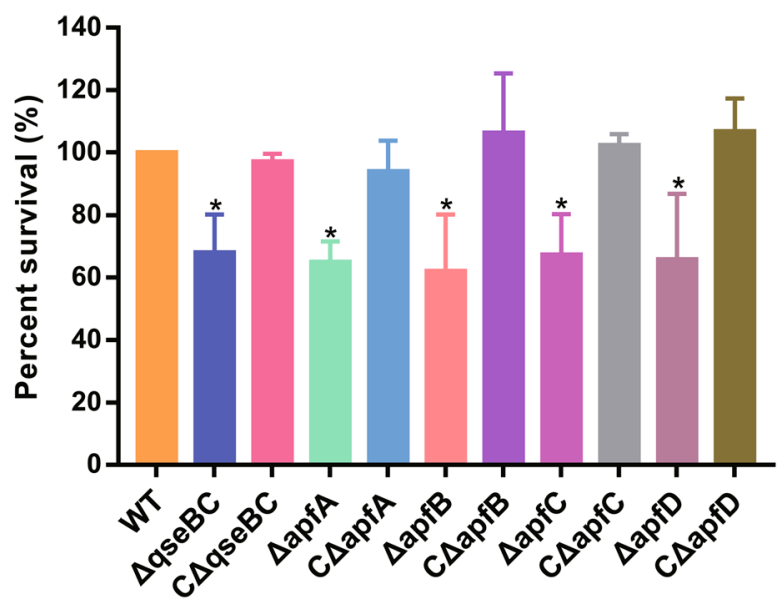

Fig. 4 Acidic and osmotic stress resistance assays. WT S4074, $\Delta q s e B C, \Delta a p f A, \Delta a p f B, \Delta a p f C$ and $\Delta a p f D$ were treated with $0.02 \mathrm{M} H C l(\mathbf{a})$ and 0.50 $\mathrm{M} \mathrm{KCl}(\mathbf{b})$ or tryptic soy broth and incubated for $3 \mathrm{~h}$ at $37^{\circ} \mathrm{C}$. Then the bacterial survival rates were calculated. Data presented are the mean $\pm \mathrm{SD}$ $(N=3) . * P<0.05$

of APP (Liu et al. 2015). We also found that the survival rates were similar in mice infected with WT or the $\triangle q s e B C$, however, it was interesting that the survival rate of mice infected with $\triangle q s e B C$ (83.33) was significantly higher than that of WT (50.00) at $6 \mathrm{~h}$. In order to further verify our result, we analyzed the bacterial colonization ability in mice tissues, and found that the amount of colonization by the $\triangle q s e B C$ in the lung and the blood were both lower than those by the WT at $6 \mathrm{~h}$ postinfection. These results suggested that QseB/QseC TCS might contribute to the virulence in the early stages of infection.

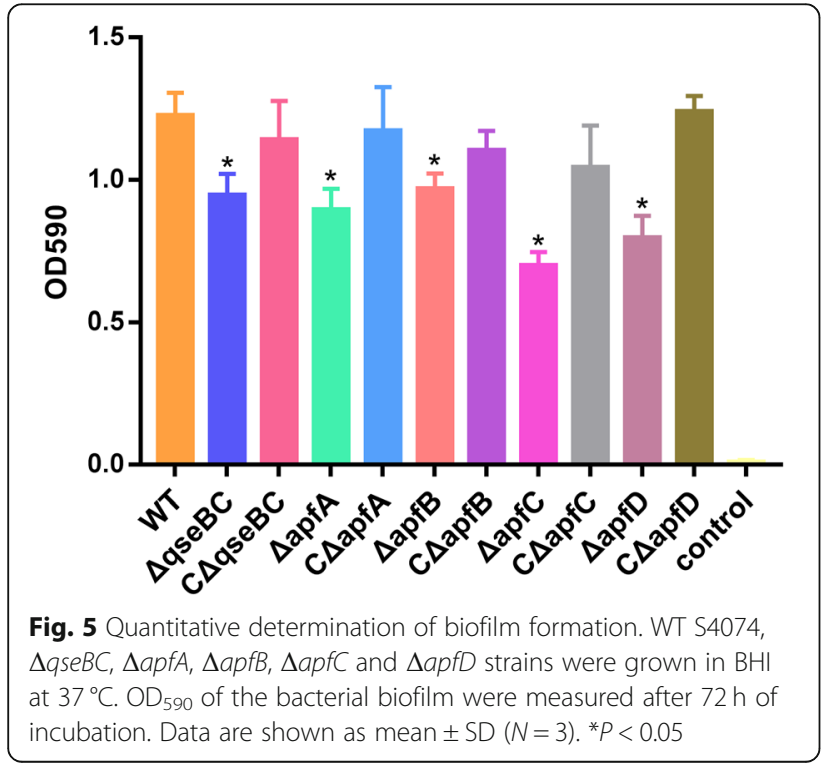

Besides, the $\triangle q s e B C$ and $\triangle a p f$ gene cluster mutants contribute to the resistance to phagocytosis. Bacteria are phagocytic and form phagosomes in phagocytes. Lysosomes fuse with phagosomes to form phagolysosomes. A variety of bactericidal substances and hydrolases in lysosomes kill and digest bacteria. The thallus residue is expelled from the cell (Cao et al. 2019). By knocking out the apf genes, the mutant strains could not synthesize the Tfp assembly protein normally and the virulence of these mutant strains were significantly weakened, which made the mutants more easier to be phagocytic by macrophage.

At the same time, the abilities of the $\triangle q s e B C$ and $\triangle a p f$ gene cluster strains to adhesion and invasion of cells were lower than that of the WT strain. Adhesion colonization is a key step for pathogen infection and pathogenesis after pathogen invasion. APP specifically colonizes the lower respiratory tract of pigs, adhering to bronchial cilia and alveolar epithelial cells (Dom et al. 1994). The results suggest that the QseB/QseC TCS can affect the expression of apf gene clusters, mediating the adhesion and invasion of APP, and thus establishing infection. To sum up, this research indicate that QseB/ QseC TCS and apf gene cluster could contribute to virulence in the early stage of infection of APP in vivo. The data in this study will provide theoretical basis for the prevention of infection with APP.

\section{Conclusions}

In summary, we confirm that QseB/QseC TCS contributes to the stress resistance, biofilm formation, phagocytosis, adhesion, invasion and virulence of APP by downregulating the expression of apf gene cluster. 

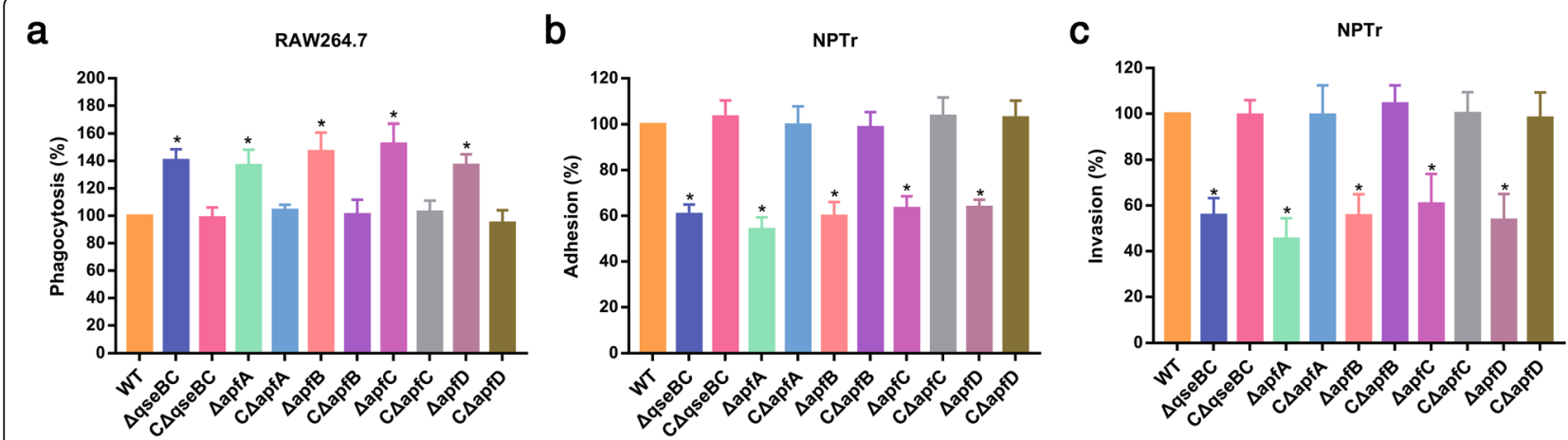

Fig. 6 Cell phagocytosis, adhesion and invasion assays. a Phagocytosis of $\triangle q s e B C, \triangle a p f A, \triangle a p f B, \triangle a p f C$ and $\triangle a p f D$ strains. The strains were incubated with RAW264.7 cells at the multiplicity of infection (MOl) of 100 at $37^{\circ} \mathrm{C}$ for $2 \mathrm{~h}$. b, c Adhesion (b) and invasion (c) of $\triangle q s e B C, \triangle a p f A$, $\triangle a p f B, \triangle a p f C$ and $\triangle a p f D$ strains. The strains were incubated with NPTr cells at the MOI of 100 for $2 \mathrm{~h}$ of incubation at $37^{\circ} \mathrm{C}$. After washing out the unbound bacteria, the NPTr cells were lysed and the bacterial counts in the lysates were determined. Data are shown as mean \pm SD $(N=3) . * P<0.05$

\section{Methods}

\section{Strains, plasmids, primers and culture conditions}

The experimental materials are listed in Tables 1 and 2. S4074 was used as WT strain of A. pleuropneumoniae (Donà and Perreten 2018). APP strains were inoculated on tryptic soy agar (TSA; Difco Laboratories, USA) containing $10 \%(v / v)$ inactivated newborn bovine serum and $10 \mu \mathrm{g} / \mathrm{mL}$ nicotinamide adenine dinucleotide (NAD; Solarbio, China), then, a single colony was selected and inoculated into tryptic soy broth (TSB; Difco Laboratories, USA). E. coli strains were cultured in Luria-Bertani (LB; Haibo, China), and the cultivation of E. coli $\beta 2155$ requires the addition of diaminopimelic acid (dapA; Sigma-Aldrich, USA) (Yuan et al. 2014). Chloramphenicol was added to the culture medium as needed, where the final concentration was $25 \mu \mathrm{g} / \mathrm{mL}$ for $E$. coli screening, $4 \mu \mathrm{g} / \mathrm{mL}$ for APP transformants screening, and $2 \mu \mathrm{g} /$ $\mathrm{mL}$ for APP complemented strains screening. All strains were oscillated in a $37^{\circ} \mathrm{C}$ incubator at $180 \mathrm{r} / \mathrm{min}$. RAW264.7 mouse macrophage cell line and NPTr (newborn piglet tracheal cell line) were cultured in Dulbecco's modified eagle medium (DMEM) (Gibco, USA) containing $10 \%(v / v)$ foetal bovine serum (FBS; Gibco, USA) (Liu et al. 2017) with $5 \%(v / v) \mathrm{CO}_{2}$ at $37^{\circ} \mathrm{C}$.

\section{Construction of mutant and complemented strains}

The mutant strains $\triangle q s e B C, \triangle a p f A, \triangle a p f B, \Delta a p f C$, $\triangle a p f D$ and the complemented strains $C \triangle q s e B C$, $C \triangle a p f A, C \Delta a p f B, C \Delta a p f C$ and $C \triangle a p f D$ were constructed as described earlier (Li et al. 2018). In Brief, the upstream and downstream fragments of qseBC, apfA, $a p f B$, apfC and apfD were amplified, respectively. And the fragments were combined via overlapping polymerase chain reaction (PCR). These products were purified and cloned into the vector pEMOC2 (Oswald et al.
1999) to generate the recombinant plasmids of $\mathrm{pE} \Delta$ qseBC, $\mathrm{pE} \triangle a p f A, \mathrm{pE} \triangle a p f B, \mathrm{pE} \triangle a p f C$ and $\mathrm{pE} \triangle a p f D$, respectively. These plasmids were used to construct $\triangle q s e B C, \triangle a p f A, \triangle a p f B, \triangle a p f C$ and $\triangle a p f D$ mutants by conjugational transfer. The qseBC and apf gene cluster were amplified and PCR products were cloned into vector pJFF224-XN (Frey 1992), respectively. Then, the plasmids pJFF-qseBC, pJFF- $\triangle a p f A$, pJFF- $\triangle a p f B$, pJFF$\triangle a p f C$ and $\mathrm{pJFF}-\triangle a p f D$ were transferred into the corresponding mutant strains by electric transformation $(2.5$ $\mathrm{KV}, 25 \mu \mathrm{FD}, 800 \Omega$ ). These mutants were screened on TSA (supplemented with chloramphenicol, NAD, and bovine serum) and verified by PCR and DNA sequencing (data not shown).

\section{RNA extraction and RT-qPCR}

WT and $\triangle q s e B C$ strains were cultured in TSB (supplemented with NAD and bovine serum) overnight, then diluted with fresh medium at a ratio of 1:100 and grown to the $\mathrm{OD}_{600}$ of 0.6. The Bacteria Total RNA Isolation Kit (Sangon Biotech, China) was used to extract total RNA. The HiScript II Q RT SuperMix (+gDNA wiper) (Vazyme, China) was used to synthesize the first strand cDNA. AceQ qPCR SYBR Green Master Mix (Vazyme, China) was used for quantitative PCR (qPCR), which performed by a one-step reaction (Walters et al. 2006). The inverted cDNA and 16S rRNA gene were used as template and endogenous control, respectively. Specific procedure, reaction system and conditions were as instructed by these kits. Then, we used the $2^{-\Delta \Delta \mathrm{Ct}}$ method to quantitatively analyze the expression level of target genes (Livak and Schmittgen 2001).

\section{Expression of QseB}

Primers PqseB-F and $\mathrm{P} q s e B-\mathrm{R}$ were used to amplify qseB gene for $\mathrm{PCR}$, and plasmid $\mathrm{pET}$-qseB was transferred 
a

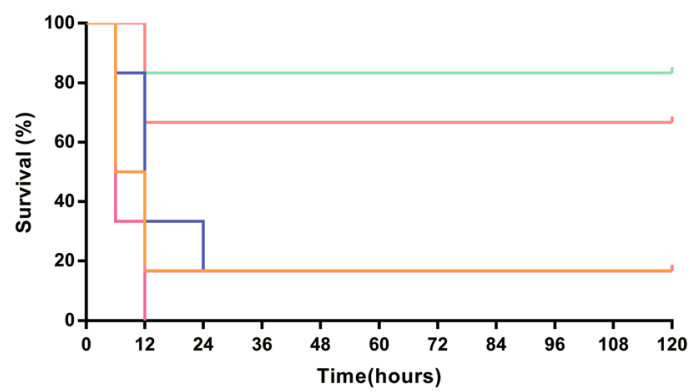

b

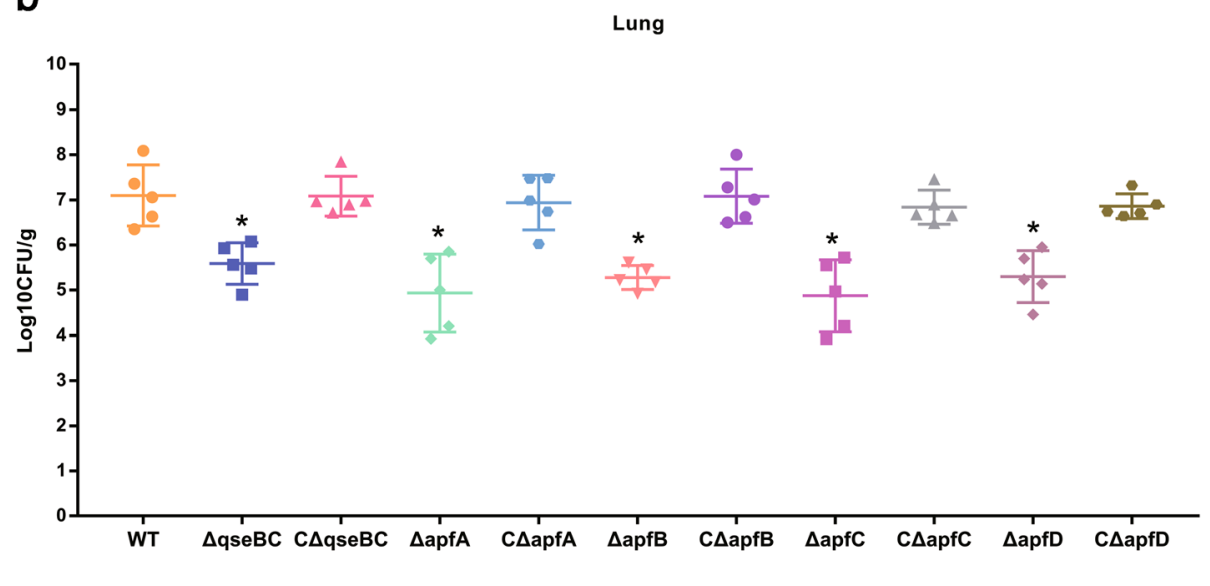

C

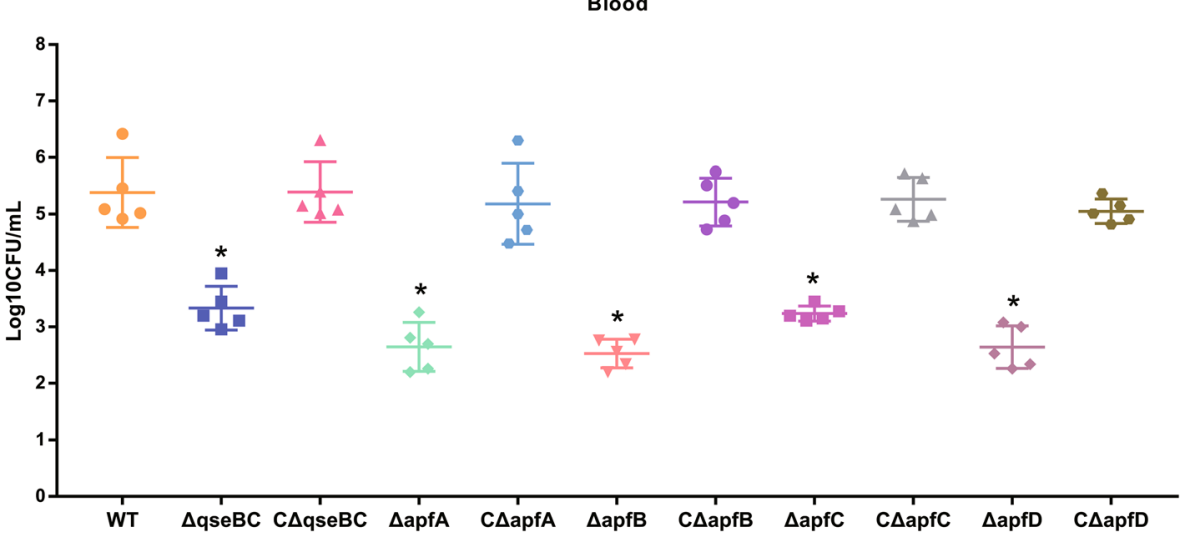

- WT

- $\triangle$ qseBC ns

- $\mathrm{C} \triangle \mathrm{qseBC}$

- $\triangle$ apfA *

- CAapfA

$-\triangle a p f B$ *

- CAapfB

- $\triangle \mathrm{apfC}$ *

- CAapfC

$+\triangle \mathrm{apfD} *$

$-\mathrm{C} \triangle \mathrm{apfD}$ b

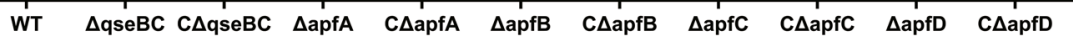

Fig. 7 Survival curves and bacteria loads of mice infected with A. pleuropneumoniae. a Survival curves for Balb/c mouse infected with WT S4074, $\triangle q s e B C, \triangle a p f A, \triangle a p f B, \triangle a p f C$ and $\triangle a p f D$ strains. Six-week-old Balb/c mice were inoculated WT S4074, $\triangle q s e B C, \triangle a p f A, \triangle a p f B, \triangle a p f C$ and $\triangle a p f D$ strains with $5.00 \times 10^{6} \mathrm{CFU}$ by intraperitoneal injection, and the survival of mice was monitored for $120 \mathrm{~h}$ post-infection. Data were analyzed by log-rank test. b, c The A. pleuropneumoniae load in lung (b) and blood (c) tissues of infected mouse. Each mice was inoculated WT S4074, $\triangle 95 \mathrm{~s} B C$, $\triangle a p f A, \triangle a p f B, \triangle a p f C$ and $\triangle a p f D$ strains with $5.00 \times 10^{6}$ CFU by intraperitoneal injection. ${ }^{*} P<0.05$

into E. coli BL21 (DE3) competent cells and grown in LB to $\mathrm{OD}_{600}$ of 0.6 . QseB protein was induced with 1.00 $\mathrm{mM}$ isopropyl- $\beta$-D-thiogalactoside (IPTG) at $25^{\circ} \mathrm{C}$ for 4 h. After suspension, cells were crushed by high-pressure cell crusher and centrifuged at $4{ }^{\circ} \mathrm{C}$. QseB was then purified by the Ni-NTA resin affinity chromatography. The purified QseB protein was analyzed by SDS-PAGE and Western Blot, then stored at $-80^{\circ} \mathrm{C}$.

\section{Electrophoretic mobility shift assays}

Primers were used to amplify DNA probes containing apf, pilM and glpK promoter region for PCR, 
Table 1 Strains, plasmids and protein used in this study

\begin{tabular}{|c|c|}
\hline $\begin{array}{l}\text { Strains or } \\
\text { plasmids }\end{array}$ & Characteristics \\
\hline \multicolumn{2}{|r|}{ A. pleuropneumoniae } \\
\hline S4074 & $\begin{array}{l}\text { A. pleuropneumoniae reference strain of serovar } 1 \text {; } \\
\text { WT strain }\end{array}$ \\
\hline$\triangle q s e B C$ & A. pleuropneumoniae $\$ 4074$ qseBC-deletion mutant \\
\hline$\triangle a p f A$ & A. pleuropneumoniae $\$ 4074$ apfA-deletion mutant \\
\hline$\triangle a p f B$ & A. pleuropneumoniae $\$ 4074$ apfB-deletion mutant \\
\hline$\triangle a p f C$ & A. pleuropneumoniae $\$ 4074$ apfC-deletion mutant \\
\hline$\Delta a p f D$ & A. pleuropneumoniae S4074 apfD-deletion mutant \\
\hline$C \Delta q s e B C$ & Complemented strain of $\triangle q s e B C ; \mathrm{Cm}^{r}$ \\
\hline$C \triangle a p f A$ & Complemented strain of $\triangle a p f A ; \mathrm{Cm}^{r}$ \\
\hline$C \triangle a p f B$ & Complemented strain of $\triangle a p f B ; \mathrm{Cm}^{r}$ \\
\hline CAapfC & Complemented strain of $\Delta a p f C ; \mathrm{Cm}^{r}$ \\
\hline$C \triangle a p f D$ & Complemented strain of $\triangle a p f D ; \mathrm{Cm}^{r}$ \\
\hline & E. coli \\
\hline $\mathrm{DH} 5 \mathrm{a}$ & Cloning host for recombinant vector \\
\hline$\beta 2155$ & $\begin{array}{l}\text { Transconjugation donor for constructing mutant } \\
\text { strain }\end{array}$ \\
\hline BL21 (DE3) & $\begin{array}{l}\text { The expression host for pET-30a and their } \\
\text { derivative }\end{array}$ \\
\hline \multicolumn{2}{|r|}{ Plasmids } \\
\hline pEMOC2 & $\begin{array}{l}\text { Transconjugation vector: ColE1 ori mob } \\
\text { RP4 sacB, } \mathrm{Amp}^{r} \mathrm{Cm}^{r}\end{array}$ \\
\hline $\mathrm{pE} \Delta q \mathrm{se} B \mathrm{C}$ & $\begin{array}{l}\text { Up- and down-stream arms of qseBC were ligated } \\
\text { sequentially into pEMOC2, and used as the } \\
\text { transconjugation vector for qseBC gene deletion }\end{array}$ \\
\hline $\mathrm{pE} \Delta a p f A$ & $\begin{array}{l}\text { Up- and down-stream arms of apfA were ligated } \\
\text { sequentially into pEMOC2, and used as the } \\
\text { transconjugation vector for apfA gene deletion }\end{array}$ \\
\hline $\mathrm{pE} \triangle a p f B$ & $\begin{array}{l}\text { Up- and down-stream arms of apfB were ligated } \\
\text { sequentially into pEMOC2, and used as the } \\
\text { transconjugation vector for apfB gene deletion }\end{array}$ \\
\hline $\mathrm{pE} \Delta a p f C$ & $\begin{array}{l}\text { Up- and down-stream arms of apfC were ligated } \\
\text { sequentially into pEMOC2, and used as the } \\
\text { transconjugation vector for apfC gene deletion }\end{array}$ \\
\hline $\mathrm{pE} \Delta a p f D$ & $\begin{array}{l}\text { Up- and down-stream arms of apfD were ligated } \\
\text { sequentially into pEMOC2, and used as the } \\
\text { transconjugation vector for apfD gene deletion }\end{array}$ \\
\hline pJFF224-XN & $\begin{array}{l}\text { E. coli-APP shuttle vector: RSF1010 replicon; } \\
\text { mob oriV, } \mathrm{Cm}^{r}\end{array}$ \\
\hline pJFF-qseBC & pJFF224-XN carrying the intact qseBC \\
\hline pJFF-apfA & pJFF224-XN carrying the intact apfA \\
\hline pJFF- $a p f B$ & pJFF224-XN carrying the intact $a p f B$ \\
\hline pJFF-apfC & pJFF224-XN carrying the intact apfC \\
\hline pJFF-apfD & pJFF224-XN carrying the intact $a p f D$ \\
\hline pET-30a & Expression vector; $\mathrm{Kan}^{\mathrm{r}}$ \\
\hline pET-qseB & pET-30a carrying qseB gene \\
\hline
\end{tabular}

$\mathrm{Cm}^{r}$, chloramphenicol resistance, $A m p^{r}$, ampicillin resistance, $\mathrm{Kan}^{r}$, kanamycin resistance respectively. After the PCR products were purified, biotin labeling of EMSA probes were carried out using the EMSA Probe Biotin Labeling Kit (Beyotime, China). QseB protein was phosphorylated by Sigma Acetate Kinase from E. coli (Sigma, USA). The pilM probe that can bind to QseB protein was used as a positive control, and $g l p K$ probe that can not bind to QseB protein was used as a negative control (Liu et al. 2015). EMSAs were performed with the Chemiluminescent EMSA Kit (Beyotime, 'China).

\section{Acidic and osmotic stress resistance assays}

WT, $\triangle q s e B C, \triangle a p f A, \triangle a p f B, \triangle a p f C$ and $\triangle a p f D$ strains were cultured in TSB (supplemented with NAD and bovine serum) overnight, then diluted with fresh medium at a ratio of 1:100 and grown to the mid-logarithmic phase. All strains were resuspended in TSB (supplemented with NAD and bovine serum) containing $0.02 \mathrm{M}$ $\mathrm{HCl}$ (Rode et al. 2010) and $0.50 \mathrm{M} \mathrm{KCl}$ (Yin and Mimura 2020), respectively, and incubated for $3 \mathrm{~h}$, followed by acidic and osmotic stress resistance assays. Bacteria cultured in TSB without any addition were used as control. The incubated samples were serially diluted and selected the appropriate dilution gradient samples to culture in TSA (supplemented with NAD and bovine serum). The bacterial survival rate of each group was determined by dividing CFU of the experimental group by that of the control group.

\section{Biofilm assay}

All strains were cultured overnight, then diluted with fresh brain heart infusion broth (BHIB; Oxoid Ltd., UK) (supplemented with NAD) at a ratio of 1:100. Totally $100 \mu \mathrm{L}$ of the inocula was added to 96-well microtiter plates (Corning, USA) in triplicat. After incubated for $72 \mathrm{~h}$, the bacterial inocula was sucked away with a syringe, and then removed unattached bacteria. Placed the plates in a warm oven to dry and added $100 \mu \mathrm{L} 0.1 \%(v /$ $v$ ) crystal violet into the well. The plates were carefully washed with tap water. After drying, 33\% ( $v / v)$ glacial acetic acid was used to dissolve the biofilm. Each well of the plates was measured $\mathrm{OD}_{590}$ with a Multi-Detection Microplate Reader (BMG Labtech, Germany).

\section{Cell phagocytosis assay}

RAW264.7 cells were cultured in 24-well plates with DMEM (supplemented with FBS) to analyze the phagocytosis ability (Carreras-Gonzalez et al. 2019). Briefly, all strains were added to RAW264.7 cells in the plates at the multiplicity of infection (MOI) of 100, respectively. After incubation for $2 \mathrm{~h}$, the mixture were treated with $100 \mu \mathrm{g} / \mathrm{mL}$ of gentamicin to kill any extracellular bacteria. Following an incubation for $45 \mathrm{~min}, 1 \mathrm{~mL}$ precooled $0.025 \%(v / v)$ Triton X-100 was used to lyse those 
Table 2 Primers used in this study

\begin{tabular}{|c|c|}
\hline Primers & Sequence $\left(5^{\prime}-3^{\prime}\right)^{\mathrm{a}}$ \\
\hline & For mutant construction \\
\hline \multirow[t]{2}{*}{ qseBC-up-F/R } & TTGTCGACCTATGGCTITAACTTCCTTCG \\
\hline & GGGAATTCATTATTGTCCGATAAAGCGAC \\
\hline \multirow[t]{2}{*}{ qseBC-down-F/R } & GGGAATTCTTAAGCCGAAGAGAAAAAGACG \\
\hline & GGTCTAGAGTCGTATCGTTTAATGCGATC \\
\hline \multirow[t]{2}{*}{ apfA-up-F/R } & CTGTCGACTITGATACCGAGCTGCAATAAGCGT \\
\hline & $\begin{array}{l}\text { GCGTTTACTTTAATTGAATTGATGAGGAAA } \\
\text { CGAAATGTAAAGGGGAGGAC }\end{array}$ \\
\hline \multirow[t]{2}{*}{ apfA-down-F/R } & $\begin{array}{l}\text { GTCCTCCCCTITACATTTCGTTTCCTCATCAATT } \\
\text { CAATTAAAGTAAACGC }\end{array}$ \\
\hline & ATGCGGCCGCCGCTACGGCTGAGGAAAATC \\
\hline \multirow[t]{2}{*}{ apfB-up-F/R } & CTGTCGACCGATAATCAGCATTAAGATCGGCTC \\
\hline & $\begin{array}{l}\text { GAAATACCTGCTCGGGCAATTAATATTGTTAT } \\
\text { CACGGCTACAGAGGC }\end{array}$ \\
\hline \multirow[t]{2}{*}{ apfB-down-F/R } & $\begin{array}{l}\text { GCCTCTGTAGCCGTGATAACAATATTAATT } \\
\text { GCCCGAGCAGGTATTC }\end{array}$ \\
\hline & ATGCGGCCGCTACATTCTTTGCATTGCCCCAT \\
\hline \multirow[t]{2}{*}{ apfC-up-F/R } & CTGTCGACGGCTTGTATTTGGCTTAACATCTCT \\
\hline & $\begin{array}{l}\text { ACAACTTCAGAAAGGAAAAGCGTATTATCGGT } \\
\text { ACGGTTTTGATCGGAT }\end{array}$ \\
\hline \multirow[t]{2}{*}{ apfC-down-F/R } & $\begin{array}{l}\text { ATCCGATCAAAACCGTACCGATAATACGCTTT } \\
\text { TCCTITCTGAAGTTGT }\end{array}$ \\
\hline & ATGCGGCCGCCGAGATTITGCTITCTTACGC \\
\hline \multirow[t]{2}{*}{ apfD-up-F/R } & CTGTCGACCATTTGCTITCCTTATCTITGCTA \\
\hline & $\begin{array}{l}\text { GTGGTGTAAGCGAAGTATTCCTCAATTTTCGA } \\
\text { CTITCGTGCTAATTATTG }\end{array}$ \\
\hline \multirow[t]{2}{*}{ apfD-down-F/R } & $\begin{array}{l}\text { CAATAATTAGCACGAAAGTCGAAAATTGAG } \\
\text { GAATACTTCGCTTACACCAC }\end{array}$ \\
\hline & $\begin{array}{l}\text { ATGCGGCCGCGCTGAATGATTTAAAC } \\
\text { CGTTTGATA }\end{array}$ \\
\hline \multirow[t]{2}{*}{ apxIVA-F/R } & GGCTACCCATTTCCCTTCG \\
\hline & GAGCAACAACGTCGCACA \\
\hline \multirow[t]{2}{*}{ qseBC-exterior-F/R } & GTTATCGGTAGGTCCACAGG \\
\hline & TGATCGCAGCAAATACCAAA \\
\hline \multirow[t]{2}{*}{ qseBC-interior-F/R } & CGGAACGACTCGCCTCTT \\
\hline & AAATCGCCAAAATCAATAGCGGTAG \\
\hline \multirow[t]{2}{*}{ apfA-exterior-F/R } & AATACCGGCTCAATTCGCTTA \\
\hline & ACCAGTCACGTAAAGGGTCGGC \\
\hline \multirow[t]{2}{*}{ apfA-interior-F/R } & GGTGTCATCGTATAACCGTATT \\
\hline & TTGGCGGCATCGGCTTCTT \\
\hline \multirow[t]{2}{*}{ apfB-exterior-F/R } & GTTGGATACGGATCTGTGAATAG \\
\hline & TTACGGTGGAAGGCGGAACGATTAC \\
\hline \multirow[t]{2}{*}{ apfB-interior-F/R } & CGCATCATTGGTATGTAAGGTC \\
\hline & GGATTCCGTGTTCGAGTT \\
\hline \multirow[t]{2}{*}{ apfC-exterior-F/R } & AGGAATACTTCGCTTACACCAC \\
\hline & GTTATCACGGCTACAGAGGC \\
\hline apfC-interior-F/R & CTAATCGCCCGCTITGTT \\
\hline
\end{tabular}

Table 2 Primers used in this study (Continued)

\begin{tabular}{|c|c|}
\hline Primers & Sequence $\left(5^{\prime}-3^{\prime}\right)^{a}$ \\
\hline & CTGAATGCCGCAGTCCCT \\
\hline \multirow[t]{2}{*}{ apfD-exterior-F/R } & CATCATCGGCATAACGCAGTC \\
\hline & AGGCGGATTAGTCGGAGGC \\
\hline \multirow[t]{3}{*}{ apfD-interior-F/R } & GCATAAACCCAGCATACCA \\
\hline & TTCCTCTGCTTGCCTTTG \\
\hline & or complement construction \\
\hline \multirow[t]{2}{*}{ qseBC-F/R } & AACTGCAGTTGCAAAATTTCAGCAAATTTAGAC \\
\hline & TTGCGGCCGCTTAGAAGATAATTTCCGCTITAAAA \\
\hline \multirow[t]{2}{*}{ apfA-F/R } & CCCTCGAGATGCAAAAACTAAGTCTTATTCGAC \\
\hline & TTGCGGCCGCTTAATTTGATGCGCAGAAATTGCC \\
\hline \multirow[t]{2}{*}{ apfB-F/R } & CCCTCGAGATGCAGTATTCCGTATGTGATGTAA \\
\hline & TTGCGGCCGCTCATACACTITCAACATGACCTAAC \\
\hline \multirow[t]{2}{*}{ apfC-F/R } & CCCTCGAGATGTTGAAAGTGTATGAATTTCATT \\
\hline & TTGCGGCCGCCTAACCGCCTCCGACTAATCCGCCT \\
\hline \multirow[t]{3}{*}{ apfD-F/R } & CCCTCGAGATGAGTTCTCCGATITCGCATGGT \\
\hline & TTGCGGCCGCTTAGATATAAATTITATCAATAATT \\
\hline & For RT-qPCR \\
\hline \multirow[t]{2}{*}{$16 \mathrm{~S} r \mathrm{RNA}-\mathrm{F} / \mathrm{R}$} & CCATGCCGCGTGAATGA \\
\hline & TTCCTCGCTACCGAAAGAACTT \\
\hline \multirow[t]{2}{*}{ apfA-qPCR-F/R } & GACCGCCGCTACAGTTITTA \\
\hline & TTGCCATTTAAGCTACGGTTG \\
\hline \multirow[t]{2}{*}{ apfB-qPCR-F/R } & CGAAGGCGCATCATTGGTAT \\
\hline & CAAACGCAAATAAACCCGGC \\
\hline \multirow[t]{2}{*}{ apfC-qPCR-F/R } & AAATTTCGCCTAATCGCCCG \\
\hline & GCCGCAGTCCCTTTAAAACA \\
\hline \multirow[t]{3}{*}{ apfD-qPCR-F/R } & TGTCCCCGCTTCCCAATATT \\
\hline & TGCTTGCCTTTGGAATTGCT \\
\hline & For protein expression \\
\hline \multirow[t]{3}{*}{ PqseB-F/R } & CGCCCATATGTTGCAAAATTTCAGCAAATTTAGAC \\
\hline & CGCCCTCGAGAGCATCTGAATTTCCTATITTA \\
\hline & For EMSAs \\
\hline \multirow[t]{2}{*}{ apf-EMSA-F/R } & ATCCCTCTCCTTATCATATCTAAGA \\
\hline & TTTGACCTCTGAATTTATTAAAACG \\
\hline \multirow[t]{2}{*}{ pilM-EMSA-F/R } & CGAAAAATTCTCTTCTGGTAAATGA \\
\hline & AATTTAGTTCCTTAAATCAACTIT \\
\hline \multirow[t]{2}{*}{ glpK-EMSA-F/R } & CGTTTCCCTIIITACGGACTAAAC \\
\hline & ATAGTCCTCCTACGGATAACGAAAA \\
\hline
\end{tabular}

${ }^{a}$ Restricton sites are underlined 
cells for $10 \mathrm{~min}$ at $4{ }^{\circ} \mathrm{C}$ or on ice. The lysates were serially diluted and selected the appropriate dilution gradient cells to plate on TSA (supplemented with NAD and bovine serum) overnight to determine bacterial counts.

\section{Cell adhesion and invasion assays}

NPTr cells were used to investigate the abilities of adhesion and invasion (Zhou et al. 2013). Briefly, all strains were added to NPTr cells at the MOI of 100 and incubated for $2 \mathrm{~h}$. For the adhesion assays, each well was lysed by using $0.025 \%(v / v)$ Triton X-100 after the culture supernatant removed. The cell lysates were serially diluted to determine bacterial counts, which may contain adherent and invasive cells. For invasion assays, gentamicin was also added to each well after washing with PBS and further cultured for $45 \mathrm{~min}$. Then, the cells were lysed and diluted in the appropriate dilution gradient for bacterial count.

\section{Bacterial virulence in vivo}

Six-week-old female Balb/c mice were purchased from Experimental Animal Center of Three Gorges University (Yichang, China). The animal ecperiments were performed as described previously, with some modifications (Li et al. 2018). To determine the survival rates, mouse were randomly divided into 11 groups (6 per group): WT, $\triangle q s e B C, \mathrm{C} \triangle q s e B C, \triangle a p f A, \mathrm{C} \triangle a p f A, \Delta a p f B$, $C \Delta a p f B, \triangle a p f C, C \Delta a p f C, \triangle a p f D$ and $C \triangle a p f D$. Briefly, all strains were grown to the $\mathrm{OD}_{600}$ of 0.6. Each mice was inoculated with $5.00 \times 10^{6} \mathrm{CFU}$ by intraperitoneal injection. Clinical symptoms and mortality rates of mice were observed and recorded every day. The surviving mice were euthanized a week later. To determine the bacterial colonization ability of mice tissues, each mice was inoculated with $1.00 \times 10^{6} \mathrm{CFU}$ by intraperitoneal injection. At $6 \mathrm{~h}$ post-infection, blood samples were collected and anticoagulated by heparin. Then the mice were humanely-euthanized and lung tissue samples were taken out about $0.1 \mathrm{~g}$ for homogenization by using a Tissuelyser (Jingxin, China). $100 \mu \mathrm{L}$ of each blood and lung sample was used for gradient dilution. CFU was calculated by appropriate dilution gradient tissue fluid cultured on TSA (supplemented with NAD and bovine serum).

\section{Statistical analysis}

Statistical analysis was performed via GraphPad Prism 7 software (San Diego, USA). The results were presented as mean $\pm \mathrm{SD}$. The survival rate of mice was analyzed by log-rank (Mantel-Cox) test. The bacterial load in mouse tissues was analyzed by two-tail Mann-Whitney test. Student's $t$ test was used to compare differences between groups, where $P<0.05$ was considered significant.

\section{Abbreviations}

APP: Actinobacillus pleuropneumoniae; BHI: Brain heart infusion; bp: Base pair; cDNA: Complementary DNA; CFU: Colony forming units; DAP: 2,6Diaminopimelic acid; dd $\mathrm{H}_{2} \mathrm{O}$ : Double distilled $\mathrm{H}_{2} \mathrm{O}$; DMEM: Dulbecco's modified eagle medium; DNA: Deoxyribonucleic acid; EMSA: Electrophoretic mobility shift assay; FBS: Foetal bovine serum; g: Gram; h: Hour;

IPTG: Isopropyl- $\beta$-D-thiogalactopyranoside; kDa: Kilodalton; LB: Luria bertani; min: Minute; MOI: Multiplicity of infection; mol: Mole; NAD: Nicotinamide adenine dinucleotide; OD: Optical density; PAGE: Polyacrylamide gel electrophoresis; PBS: Phosphate buffered saline; PCP: Porcine contagious pleuropneumonia; PCR: Polymerase chain reaction; RT-qPCR: Quantitative reverse transcription $P C R$; r/min: Rotation per minute; RNA: Ribonucleic acid; sec: Second; SDS: Sodium dodecylsulphate; SPF: Specific pathogen free; TCS: Two-component system; TSA: Tryptic soy agar; TSB: Tryptic soy broth; $\mu \mathrm{L}$ : Microliter; ${ }^{\circ} \mathrm{C}$ : Degree centigrade

\section{Acknowledgements}

We appreciated Prof. Hongbo Zhou at Huazhong Agricultural University for providing NPTr cells. At the same time, we thank Mr. Jinlin Liu, Ms. Beibei Dou, Ms. Linlin Hu and Ms. Dan Yang for providing warm help.

\section{Authors' contributions}

$\mathrm{BD}$ and WB conceived of the study, and participated in its design and coordination. BD and WP constructed the mutant and complemented strains. BD, JT and FenY participated in the animal assays. BD, KY and FL performed the statistical analysis. BD drafted the manuscript. WB, FanY and $\mathrm{HC}$ directed the project. All authors have read and approved the final version of the manuscript.

\section{Funding}

This work was supported by grants from the Technique Innovation Program of Hubei Province (No. 2018ABA108) and the National Pig Industry Technology System (No. CARS-35)

\section{Availability of data and materials}

Data will be shared upon request by the readers.

\section{Declarations}

Ethics approval and consent to participate

All animal assays were performed according to the guidelines of the Laboratory Animal Monitoring Committee of Huazhong Agricultural University (HZAUMO-2020-083).

Consent for publication

Not applicable.

\section{Competing interests}

Author Huanchun Chen was not involved in the journal's review or decisions related to this manuscript. The authors declare no other conflict of interest

\section{Author details}

${ }^{1}$ State Key Laboratory of Agricultural Microbiology, College of Veterinary Medicine, Huazhong Agricultural University, Wuhan, China. ${ }^{2}$ The Cooperative Innovation Center for Sustainable Pig Production, Huazhong Agricultural University, Wuhan, China. ${ }^{3}$ Key Laboratory of Prevention and Control Agents for Animal Bacteriosis (Ministry of Agriculture), Institute of Animal Husbandry and Veterinary Sciences, Hubei Academy of Agricultural Sciences, Wuhan, China. ${ }^{4}$ Hubei Hongshan Laboratory, Wuhan, China. ${ }^{5}$ Guangxi Yangxiang Co., Ltd, Guigang, China.

Received: 22 November 2021 Accepted: 4 January 2022

Published online: 27 January 2022

\section{References}

Bearson, B.L., and S.M. Bearson. 2008. The role of the QseC quorum-sensing sensor kinase in colonization and norepinephrine-enhanced motility of Salmonella enterica serovar Typhimurium. Microbial Pathogenesis 44 (4): 271278. https://doi.org/10.1016/j.micpath.2007.10.001

Bosse, J.T., Y. Li, R. Fernandez Crespo, S. Lacouture, M. Gottschalk, R. Sarkozi, et al. 2018. Comparative sequence analysis of the capsular polysaccharide loci of 
Actinobacillus pleuropneumoniae serovars 1-18, and development of two multiplex PCRs for comprehensive capsule typing. Veterinary Microbiology 220: 83-89. https://doi.org/10.1016/j.vetmic.2018.05.011.

Buelow, D.R., and T.L. Raivio. 2010. Three (and more) component regulatory systems - auxiliary regulators of bacterial histidine kinases. Molecular Microbiology 75 (3): 547-566. https://doi.org/10.1111/j.1365-2958.2009.06982.x.

Cao, Y., J. Chen, G. Ren, Y. Zhang, X. Tan, and L. Yang. 2019. Punicalagin Prevents Inflammation in LPS-Induced RAW264.7 Macrophages by Inhibiting FoxO3a/ Autophagy Signaling Pathway. Nutrients 11 (11): 2794. https://doi.org/10.33 90/nu11112794.

Carreras-Gonzalez, A., D. Barriales, A. Palacios, M. Montesinos-Robledo, N. Navasa, M. Azkargorta, et al. 2019. Regulation of macrophage activity by surface receptors contained within Borrelia burgdorferi-enriched phagosomal fractions. PLoS Pathogens 15 (11): e1008163. https://doi.org/10.1371/journal. ppat.1008163.

Chiers, K., T. De Waele, F. Pasmans, R. Ducatelle, and F. Haesebrouck. 2010. Virulence factors of Actinobacillus pleuropneumoniae involved in colonization, persistence and induction of lesions in its porcine host. Veterinary Research 41 (5): 65. https://doi.org/10.1051/vetres/2010037.

Clarke, M.B., D.T. Hughes, C. Zhu, E.C. Boedeker, and V. Sperandio. 2006. The QseC sensor kinase: a bacterial adrenergic receptor. Proceedings of the National Academy of Sciences of the United States of America 103 (27): 10420-10425. https://doi.org/10.1073/pnas.0604343103.

Dom, P., F. Haesebrouck, R. Ducatelle, and G. Charlier. 1994. In vivo association of Actinobacillus pleuropneumoniae serotype 2 with the respiratory epithelium of pigs. Infection and Immunity 62 (4): 1262-1267. https://doi.org/10.1128/iai. 62.4.1262-1267.

Donà, V., and V. Perreten. 2018. Comparative Genomics of the First and Complete Genome of "Actinobacillus porcitonsillarum" Supports the Novel Species Hypothesis. International Journal of Genomics 2018: 5261719. https://doi.org/1 $0.1155 / 2018 / 5261719$

Frey, J. 1992. Construction of a broad host range shuttle vector for gene cloning and expression in Actinobacillus pleuropneumoniae and other Pasteurellaceae. Research in Microbiology 143 (3): 263-269. https://doi.org/1 0.1016/0923-2508(92)90018-j.

González, W., Giménez-Lirola, L.G., Holmes, A., Lizano, S., Goodell, C., Poonsuk, K. Sitthicharoenchai, P., Sun, Y., Zimmerman, J. 2017. Detection of Actinobacillus Pleuropneumoniae ApxIV Toxin Antibody in Serum and Oral Fluid Specimens from Pigs Inoculated Under Experimental Conditions. Veterinary Research 61 (2): 163-171. https://doi.org/10.1515/jvetres-2017-0021.

Jacob-Dubuisson, F., A. Mechaly, J.M. Betton, and R. Antoine. 2018. Structural insights into the signalling mechanisms of two-component systems. Nature Reviews. Microbiology 16 (10): 585-593. https://doi.org/10.1038/s41579-018-0055-7.

Ji, Y., W. Li, Y. Zhang, L. Chen, Y. Zhang, X. Zheng, X. Huang, and B. Ni. 2017. QseB mediates biofilm formation and invasion in Salmonella enterica serovar Typhi. Microbial Pathogenesis 104: 6-11. https://doi.org/10.1016/j.micpath.201 7.01.010.

Kaplan, J.B., and M.H. Mulks. 2005. Biofilm formation is prevalent among field isolates of Actinobacillus pleuropneumoniae. Veterinary Microbiology 108 (12): 89-94. https://doi.org/10.1016/j.vetmic.2005.02.011.

Kaplan, J.B., K. Velliyagounder, C. Ragunath, H. Rohde, D. Mack, J.K. Knobloch, and N. Ramasubbu. 2004. Genes involved in the synthesis and degradation of matrix polysaccharide in Actinobacillus actinomycetemcomitans and Actinobacillus pleuropneumoniae biofilms. Journal of Bacteriology 186 (24): 8213-8220. https://doi.org/10.1128/JB.186.24.8213-8220.2004.

Khajanchi, B.K., E.V. Kozlova, J. Sha, V.L. Popov, and A.K. Chopra. 2012. The twocomponent QseBC signalling system regulates in vitro and in vivo virulence of Aeromonas hydrophila. Microbiology 158 (Pt1): 259-271. https://doi.org/1 0.1099/mic.0.051805-0.

Labrie, J., G. Pelletier-Jacques, V. Deslandes, M. Ramjeet, E. Auger, J.H. Nash, et al. 2010. Effects of growth conditions on biofilm formation by Actinobacillus pleuropneumoniae. Veterinary Research 41 (1): 3. https://doi.org/10.1051/ vetres/2009051.

Lerat, E., Moran, N.A. 2004. The evolutionary history of quorum-sensing systems in bacteria. Molecular Biology and Evolution 21 (5): 903-13. https://doi.org/1 0.1093/molbev/msh097.

Li, H., F. Liu, W. Peng, K. Yan, H. Zhao, T. Liu, H. Cheng, P. Chang, F. Yuan, H. Chen, and W. Bei. 2018. The CpxA/CpxR two-component system affects biofilm formation and virulence in Actinobacillus pleuropneumoniae. Frontiers in Cellular and Infection Microbiology 8: 72. https://doi.org/10.3389/fcimb.2018. 00072 eCollection 2018
Li, J., Q. Fan, M. Jin, C. Mao, H. Zhang, X. Zhang, L. Sun, D. Grenier, L. Yi, X. Hou, and Y. Wang. 2021. Paeoniflorin reduce luxS/Al-2 system-controlled biofilm formation and virulence in Streptococcus suis. Virulence 12 (1): 3062-3073. https://doi.org/10.1080/21505594.2021.2010398.

Li, L., Z. Xu, Y. Zhou, T. Li, L. Sun, H. Chen, and R. Zhou. 2011. Analysis on Actinobacillus pleuropneumoniae LuxS regulated genes reveals pleiotropic roles of LuxS/AI-2 on biofilm formation, adhesion ability and iron metabolism. Microbial Pathogenesis 50 (6): 293-302. https://doi.org/10.1016/j. micpath.2011.02.002.

Li, W., M. Xue, L. Yu, K. Qi, J. Ni, X. Chen, R. Deng, F. Shang, and T. Xue. 2020. QseBC is involved in the biofilm formation and antibiotic resistance in Escherichia coli isolated from bovine mastitis. PeerJ 8: e8833. https://doi.org/1 0.7717/peerj.8833.

Liu, F., J. Fu, C. Liu, J. Chen, M. Sun, H. Chen, C. Tan, and X. Wang. 2017. Characterization and distinction of two flagellar systems in extraintestinal pathogenic Escherichia coli PCN033. Microbiological Research 196: 69-79. https://doi.org/10.1016/j.micres.2016.11.013.

Liu, J., L. Hu, Z. Xu, C. Tan, F. Yuan, S. Fu, H. Cheng, H. Chen, and W. Bei. 2015. Actinobacillus pleuropneumoniae two-component system QseB/QseC regulates the transcription of PilM, an important determinant of bacterial adherence and virulence. Veterinary Microbiology 177 (1-2): 184-192. https:// doi.org/10.1016/j.vetmic.2015.02.033.

Livak, K.J., and T.D. Schmittgen. 2001. Analysis of relative gene expression data using real-time quantitative PCR and the $2^{-\Delta \Delta C t}$ method. Methods 25 (4): 402-408. https://doi.org/10.1006/meth.2001.1262.

Mukherjee, S., and B.L. Bassler. 2019. Bacterial quorum sensing in complex and dynamically changing environments. Nature Reviews Microbiology 17 (6): $371-$ 382. https://doi.org/10.1038/s41579-019-0186-5.

Novak, E.A., H. Shao, C.A. Daep, and D.R. Demuth. 2010. Autoinducer-2 and QseC control biofilm formation and in vivo virulence of Aggregatibacter actinomycetemcomitans. Infection and Immunity 78 (7): 2919-2926. https:// doi.org/10.1128/IAl.01376-09.

Oswald, W., W. Tonpitak, G. Ohrt, and G. Gerlach. 1999. A single-step transconjugation system for the introduction of unmarked deletions into Actinobacillus pleuropneumoniae serotype 7 using a sucrose sensitivity marker. FEMS Microbiology Letters 179 (1): 153-160. https://doi.org/10.1111/j.1574-6968.1999.tb08721.x.

Rode, T.M., T. Møretrø, S. Langsrud, O. Langsrud, G. Vogt, and A. Holck. 2010. Responses of Staphylococcus aureus exposed to $\mathrm{HCl}$ and organic acid stress. Canadian Journal of Microbiology 56 (9): 777-792. https://doi.org/10.1139/w10-057.

Sassu, E.L., J.T. Bosse, T.J. Tobias, M. Gottschalk, P.R. Langford, and I. HennigPauka. 2018. Update on Actinobacillus pleuropneumoniae-knowledge, gaps and challenges. Transboundary and Emerging Diseases 65 (Suppl. 1): 72-90. https://doi.org/10.1111/tbed.12739.

Stringer, O.W., J.T. Bossé, S. Lacouture, M. Gottschalk, L. Fodor, Ø. Angen, E. Velazquez, P. Penny, L. Lei, P.R. Langford, and Y. Li. 2021. Proposal of Actinobacillus pleuropneumoniae serovar 19, and reformulation of previous multiplex PCRs for capsule-specific typing of all known serovars. Veterinary Microbiology 255: 109021. https://doi.org/10.1016/j.vetmic.2021.109021.

To, H., M. Kon, F. Koike, K. Shibuya, S. Nagai, M. Gottschalk, J. Frey, and C. Sasakawa. 2021. Proposal of a subtype of serovar 4, K4b:O3, of Actinobacillus pleuropneumoniae based on serological and genotypic analysis. Veterinary Microbiology 263: 109279. https://doi.org/10.1016/j.vetmic.2021.109279.

Vogt, S.L., and T.L. Raivio. 2012. Just scratching the surface: an expanding view of the Cpx envelope stress response. FEMS Microbiology Letters 326 (1): 2-11. https://doi.org/10.1111/j.1574-6968.2011.02406.x.

Walters, M., M.P. Sircili, and V. Sperandio. 2006. Al-3 synthesis is not dependent on luxS in Escherichia coli. Journal of Bacteriology 188 (16): 5668-5681. https://doi.org/10.1128/JB.00648-06.

Weigel, W.A., and D.R. Demuth. 2016. QseBC, a two-component bacterial adrenergic receptor and global regulator of virulence in Enterobacteriaceae and Pasteurellaceae. Molecular Oral Microbiology 31 (5): 379-397. https://doi. org/10.1111/omi.12138.

Xie, F., G. Li, Y. Zhang, L. Zhou, S. Liu, and S. Liu. 2016. The Lon protease homologue LonA, not LonC, contributes to the stress tolerance and biofilm formation of Actinobacillus pleuropneumoniae. Microbial Pathogenesis 93: 38-43. https://doi.org/10.1016/j.micpath.2016.01.009.

Xu, Z., Y. Zhou, L. Li, R. Zhou, S. Xiao, Y. Wan, S. Zhang, K. Wang, W. Li, L. Li, H. Jin, M. Kang, B. Dalai, T. Li, L. Liu, Y. Cheng, L. Zhang, T. Xu, H. Zheng, S. Pu, B. Wang, W. Gu, X.L. Zhang, G.F. Zhu, S. Wang, G.P. Zhao, and H. Chen. 2008. Genome biology of Actinobacillus pleuropneumoniae JL03, an isolate of serotype 3 prevalent in China. PLoS One 3 (1): e1450. https://doi.org/10.1371/journal.pone.0001450. 
Yan, K., T. Liu, B. Duan, F. Liu, M. Cao, W. Peng, Q. Dai, H. Chen, F. Yuan, and W. Bei. 2020. The CpxAR Two-Component System Contributes to Growth, Stress Resistance, and Virulence of Actinobacillus pleuropneumoniae by Upregulating wecA Transcription. Frontiers in Microbiology 11: 1026. https:// doi.org/10.3389/fmicb.2020.01026.

Yang, Y., P. Hu, L. Gao, X. Yuan, P.R. Hardwidge, T. Li, P. Li, F. He, Y. Peng, and N. Li. 2021. Deleting qseC downregulates virulence and promotes crossprotection in Pasteurella multocida. Veterinary Research 52 (1): 140. https:// doi.org/10.1186/s13567-021-01009-6.

Yin, Y., and H. Mimura. 2020. Mitigation of Hyper $\mathrm{KCl}$ Stress at $42^{\circ} \mathrm{C}$ with Externally Existing Sodium Glutamate to a Halotolerant Brevibacterium sp. JCM 6894. Biocontrol Science 25 (3): 139-147. https://doi.org/10.4265/bio.2 5.139 .

Yuan, F., Y. Liao, W. You, Z. Liu, Y. Tan, C. Zheng, BinWang, D. Zhou, Y. Tian, and W. Bei. 2014. Deletion of the znuA virulence factor attenuates Actinobacillus pleuropneumoniae and confers protection against homologous or heterologous strain challenge. Veterinary Microbiology 174 (3-4): 531-539. https://doi.org/10.1016/j.vetmic.2014.10.016

Zhou, Y., L. Li, Z. Chen, H. Yuan, H. Chen, and R. Zhou. 2013. Adhesion protein ApfA of Actinobacillus pleuropneumoniae is required for pathogenesis and is a potential target for vaccine development. Clinical and Vaccine Immunology 20 (2): 287-294. https://doi.org/10.1128/CVI.00616-12.

\section{Publisher's Note}

Springer Nature remains neutral with regard to jurisdictional claims in published maps and institutional affiliations.

Ready to submit your research? Choose BMC and benefit from:

- fast, convenient online submission

- thorough peer review by experienced researchers in your field

- rapid publication on acceptance

- support for research data, including large and complex data types

- gold Open Access which fosters wider collaboration and increased citations

- maximum visibility for your research: over $100 \mathrm{M}$ website views per year

At BMC, research is always in progress.

Learn more biomedcentral.com/submissions 